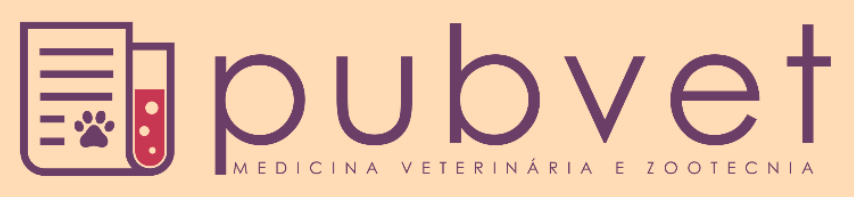

https://doi.org/10.31533/pubvet.v13n2a263.1-8

\title{
Cinomose canina: aspectos relacionados ao diagnóstico, tratamento e vacinação
}

\author{
Cintia Gonçalves Vasconcelos Freire ${ }^{1 \bullet}$, Maria Eugênia Moraes $^{2^{*}} \bullet$ \\ ${ }^{I}$ Médica veterinária. Guarulhos, SP, Brasil. \\ ${ }^{2}$ Médica Veterinária, Prof ${ }^{a}$ Mestre da Universidade Guarulhos e da Fundação de Ensino Superior de Bragança Paulista, \\ Departamento de Medicina Veterinária. Guarulhos, SP, Brasil \\ *Autor para correspondência, E-mail: eugeniavet@gmail.com
}

\begin{abstract}
Resumo. A cinomose é uma doença infecciosa altamente contagiosa com sinais e sintomas inespecíficos. Sua evolução depende de fatores imunes de cada indivíduo, podendo evoluir para o óbito. O diagnóstico geralmente é clínico devido aos sintomas apresentados e podem-se solicitar exames complementares, bem como hemograma, teste ELISA, RT-PCR e imunofluorescência indireta. O tratamento instituído é de suporte e variável de acordo com a clínica apresentada. A profilaxia e manejo devem ser orientados e inclui vacinação com protocolo determinado, ingestão de colostro, controle ambiental com higienização adequada e isolamento de animais infectados.
\end{abstract}

Palavras chave: doenças de cães, doenças infecciosas, morbillivirus

\section{Canine distemper: aspects related to diagnosis, treatment and vaccination}

\begin{abstract}
Distemper is a highly contagious infectious disease with nonspecific signs and symptoms. Its evolution depends on immune factors of each individual, and may evolve to death. The diagnosis is usually clinical because of the symptoms presented and complementary examinations can be requested, as well as blood count, ELISA, PCR and indirect immunofluorescence tests. The treatment instituted is supportive and variable according to the clinical presentation. Prophylaxis and management should be targeted and include vaccination with a protocol, colostrum ingestion, environmental control with adequate hygiene and isolation of infected animals.
\end{abstract}

Keywords: dog diseases, infectious diseases, morbillivirus

\section{Cinomosis canina: aspectos relacionados al diagnóstico, tratamiento y vacunación}

Resumen. La cinomosis es una enfermedad infecciosa altamente contagiosa con signos y síntomas inespecíficos. Su evolución depende de factores inmunes de cada individuo, pudiendo evolucionar hacia el óbito. El diagnóstico generalmente es clínico debido a los síntomas presentados y se pueden solicitar exámenes complementarios, así como hemograma, prueba ELISA, PCR e inmunofluorescencia indirecta. El tratamiento instituido es de soporte y variable de acuerdo con la clínica presentada. La profilaxis y manejo deben ser orientados e incluye vacunación con protocolo determinado, ingestión de calostro, control ambiental con higienización adecuada y aislamiento de animales infectados.

Palabras clave: enfermedades de los perros, enfermedades infecciosas, morbillivirus 


\section{Introdução}

A cinomose é uma doença infecciosa altamente contagiosa, causada por um Morbillivirus da família Paramyxoviridae. Tem distribuição mundial e mantém índices altos de óbito. Acomete geralmente os animais da ordem Carnívora, sendo eles: cães, raposas, guaxinins, ferrets, hienas, leões, tigres, pandas vermelhos, focas, entre outros (Cubas et al., 2014; Jericó et al., 2015).

Os sinais são inespecíficos e tem características aguda a subaguda, incluindo manifestações gastrointestinais, respiratórias e neurológicas. O tratamento é sintomático e, portanto, deve ser avaliado de acordo com a evolução da doença (Crivellentin \& Borin-Crivelletin, 2015). Estima-se maior incidência em períodos em que há falhas no sistema imune, possibilitando a infecção em qualquer idade, bem como quando há diminuição da taxa de anticorpos maternos, geralmente em animais com 60 a 90 dias de idade (Brito et al., 2016).

Os métodos diagnósticos incluem o histórico do animal, RT-PCR, imunofluorescência indireta, ELISA, exame histopatológico, ensaios imunohistoquímicos e a visualização de corpúsculos de inclusão (Lentz) no esfregaço sanguíneo periférico, tornando-se patognomônico para cinomose. O corpúsculo de inclusão do vírus da cinomose também pode estar presente nos tecidos da pelve renal, vesícula urinária, conjuntiva, coxins digitais e estômago (Jericó et al., 2015). Os corpúsculos de Lentz são resquícios da replicação viral que foram depositadas na célula e apresentam-se de forma intracelular, com característica eosinofílica (Silva et al., 2017).

A profilaxia e manejo devem ser orientados e inclui vacinação com protocolo determinado, ingestão de colostro quando possível e controle ambiental com higienização adequada e isolamento de animais infectados (Greene et al., 1993).

O objetivo deste trabalho foi realizar uma revisão bibliográfica abordando os aspectos relacionados ao diagnóstico e tratamento da cinomose e também aspectos relacionados a vacinação para prevenção desta doença.

\section{Material e métodos}

Realização de levantamento bibliográfico e revisão de literatura baseados em livros e artigos científicos disponíveis em bases de dados Capes, PubMed e Google Acadêmico, com abordagem da etiologia, patogenia e manifestações clínicas, diagnóstico, tratamento e profilaxia.

\section{Etiologia}

A cinomose é causada por um vírus do gênero Morbillivirus, família Paramyxoviridae. O agente possui diferentes cepas, algumas altamente virulentas e neurotrópicas. $\mathrm{O}$ vírus possui um único filamento de RNA negativo e é envolto por envelope com glicoproteínas virais $\mathrm{H}$ e F (proteína de inserção, proteína de fusão, respectivamente), conforme observado na figura 1. Estas são responsáveis por ligarem-se a receptores nas células e disseminarem a doença em diversos tecidos. Acredita-se que a disseminação em animais silvestres ocorra por alterações moleculares no gene da hemaglutinina (Greene \& Vandevelde, 2015). O vírus tem capacidade de replicação em tecidos linfoides, nervoso e epitelial e apresenta-se em amostras de fezes, urina, saliva, conteúdos respiratórios e exsudatos conjuntivais por até 60 a 90 dias após ter ocorrido à infecção (Nelson \& Couto, 2015). Sua disseminação ocorre por meio do contato direto com secreções que contenham o vírus (aerossóis, secreção oro nasal, urina e fezes). A doença apresenta-se geralmente em animais jovens não vacinados, ocorrendo de forma aguda e com manifestações clínicas inespecíficas, dificultando o diagnóstico precoce (Tozato et al., 2016). Jericó et al. (2015) descrevem que há transmissão vertical, embora seja raro.

Segundo Greene \& Vandevelde (2015) o vírus da cinomose é sensível à luz ultravioleta, ao calor e ao ressecamento, facilitando a desinfecção dos locais e fômites que tiveram contato com animais que contraíram a doença. $\mathrm{O}$ agente pode ser destruído em 30 minutos a temperaturas entre $50^{\circ}$ a $60^{\circ} \mathrm{C}$, porém permanece estável e altamente viável por longo período em temperaturas próximas ou abaixo do congelamento $\left(-65^{\circ}\right.$ a $\left.4^{\circ} \mathrm{C}\right)$ e com variação do $\mathrm{pH}$ entre 4,5 e 9 . Procedimentos de desinfecção a base de éter e clorofórmio, solução diluída de formol (menor que $0,5 \%$ ), fenol a $0,75 \%$ e produtos a base de amônio quaternário a $0,3 \%$ são capazes de eliminar o vírus do ambiente. 

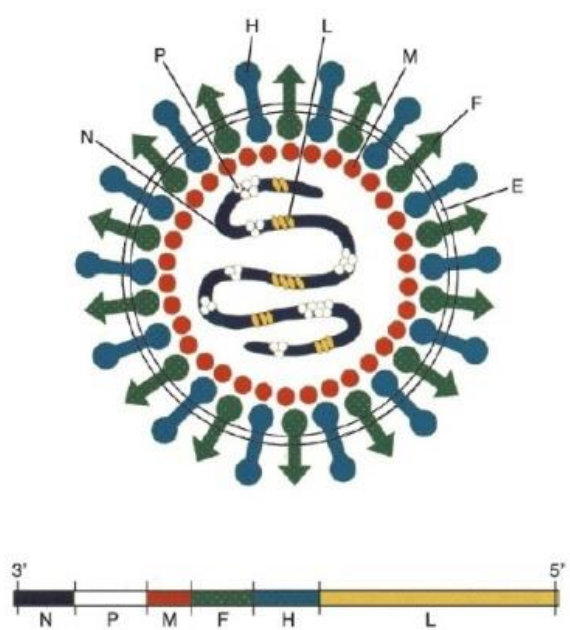

Figura 1. Estrutura do vírus da cinomose (E: envelope de lipoproteína; F: proteína de fusão; H: hemaglutinina; L: proteína grande; M: proteína da matriz; N: nucleocapsídio). Fonte: Greene \& Vandevelde (2015).

\section{Patogenia e manifestações clínicas}

A infecção ocorre por contato direto ou por aerossóis. Após 24 horas de inoculação, há multiplicação e disseminação do vírus para as tonsilas e para os linfonodos brônquicos. Em quatro a seis dias há multiplicação viral generalizada provocando leucopenia e aumento da temperatura corporal. A intensidade da infecção e dos sinais depende da resposta imunológica e da cepa viral em questão, porém a imunossupressão predispõe a infecções secundárias, sendo comuns quadros de gastroenterites, broncopneumonias, dermatites e conjuntivite (Greene \& Vandevelde, 2015; Jericó et al., 2015).

$\mathrm{O}$ vírus da cinomose tem replicação inicial no epitélio e tecido linfoide, progredindo para a forma disseminada (Jericó et al., 2015; Zachary et al., 2012). Após a disseminação o vírus destrói pneumócitos, células dos bronquíolos e macrófagos da região dos alvéolos, o que predispõe a infecções secundárias e diminui a oxigenação. Neste quadro é comum que o animal apresente broncopneumonia supurativa. Em nível do sistema digestório, o vírus da cinomose destrói os enterócitos e pode provocar diarreia. Em animais que conseguem a recuperação, pode ocorrer hipoplasia do esmalte dentário, pois o vírus acometeu o desenvolvimento de brotos dentários e ameloblastos (Zachary et al., 2012).

Alguns animais apresentam hiperqueratose nos coxins e nas narinas; pois segundo Greene \& Vandevelde (2015), durante o período virêmico os vírus que atingiram o epitélio causam proliferação dos queratinócitos basais. Os animais acometidos acabam apresentando alta taxa de encefalomielite não supurativa aguda. Após esta fase, um processo de desmielinização pode ocorrer e causar danos de caráter nervoso irreversíveis. A sintomatologia nervosa pode apresentar-se de maneiras diversas, pois depende da área acometida. De forma geral, podem surgir inclinações da cabeça, convulsões, nistagmo, paralisia parcial ou total, andar compulsivo, mioclonia, tremores, hiperestesia e cegueira (Jericó et al., 2015; Zachary et al., 2012).

Devido à característica da evolução da doença, podendo ou não causar sintomatologia neurológica, a cinomose é incluída nos testes laboratoriais para realizar o diferencial para doenças que possam provocar sinais de acometimento do sistema nervoso central (Macedo et al., 2016). O vírus pode levar a um quadro de polioencefalomielite por acometimento da substância cinzenta e ou leucoencefalomielite desmielinizante por acometimento da substância branca (Zachary et al., 2012). Cowell \& Tyler (2009) apontam que na cinomose crônica, comum em animais mais velhos e por vezes vacinados, o líquido cefalorraquidiano pode não apresentar alterações ou ter uma pleocitose mononuclear moderada, bem como um aumento discreto na concentração de proteínas.

As alterações comuns no hemograma são anemia, leucopenia, linfopenia, eosinopenia e trombocitopenia (Silva et al., 2017). Mangia \& Paes (2008) sugerem que a trombocitopenia ocorra por aumento de anticorpos antiplaquetas, sendo, portanto, imunomediada na cinomose. 


\section{Diagnóstico}

A identificação do RNA viral é muito utilizada por meio do PCR, pois é um diagnóstico com boa especificidade, já a sensibilidade depende da amostra utilizada. Recomenda-se o concentrado leucoplaquetário ou o esfregaço conjuntival em fase aguda. Para a fase crônica a urina, soro, líquido cefalorraquidiano ou sangue total podem ser utilizados (Bento et al., 2013).

Segundo Greene \& Vandevelde (2015) a utilização do sangue ou urina para PCR foram mais sensíveis que outras amostras indicadas, porém, o teste diagnóstico não diferencia o vírus vacinal do vírus natural, podendo levar a um resultado falso positivo. Outra possibilidade diagnóstica inclui a sorologia por imunofluorescência indireta e ou ELISA, porém, se o resultado for positivo, deve-se avaliar a condição imunológica do animal e levar em consideração se houve vacinação recente (Gutiérrez et al., 2015).

Greene \& Vandevelde (2015) apontam que a imunofluorescência tem melhor resultado em casos agudos, pois em fase crônica a titulação do anticorpo ou a eliminação do antígeno podem produzir resultados equivocados. De acordo com Bento et al. (2013) a titulação de anticorpos estará aumentada e pode interferir no teste de RT-PCR, dando falso positivo em caso de uso de vacina viva modificada. A técnica da imunoperoxidase pode ser utilizada para o diagnóstico e consiste em encontrar os antígenos do vírus da cinomose por meio de biópsias de pele do animal acometido (Zachary et al., 2012). Outro recurso a ser solicitado é a imunofluorescência de esfregaços da conjuntiva. Inclusões nas células epiteliais (figura 2) podem ser encontradas, embora sejam raras (Cowell \& Tyler, 2009).

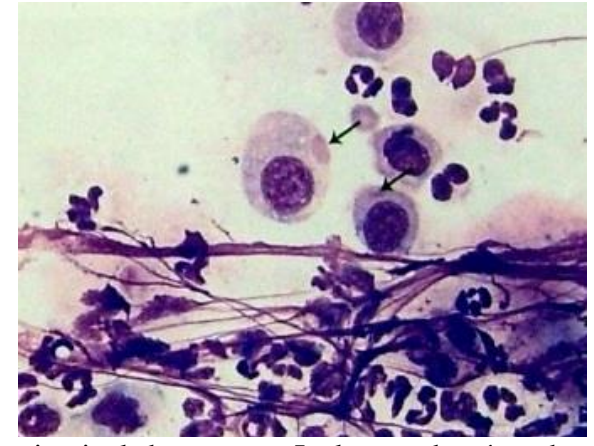

Figura 2. Raspado conjuntival de um cão. Inclusões do vírus da cinomose de tamanhos variados (setas) são encontradas dentro das células epiteliais. Fonte: Cowell \& Tyler (2009).

Para diagnóstico post mortem recomenda-se utilizar amostras do pulmão, vesícula urinária, sistema nervoso central e tecido linfoide para detecção viral através de imunofluorescência direta (Gutiérrez et al., 2015). Inclusões virais nos eritrócitos podem estar presentes, sendo o achado, patognomônico para cinomose, conforme figuras 3 e 4 (Thrall, 2015).

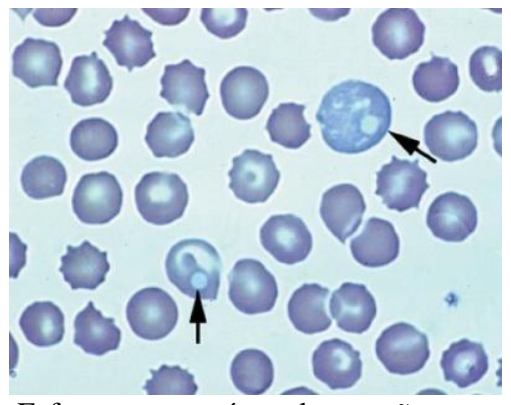

Figura 3. Esfregaço sanguíneo de um cão com cinomose Há inclusões virais de cor azul clara (setas). A coloração das inclusões pode variar de azul-claro a magenta-escuro. Fonte: Thrall (2015).

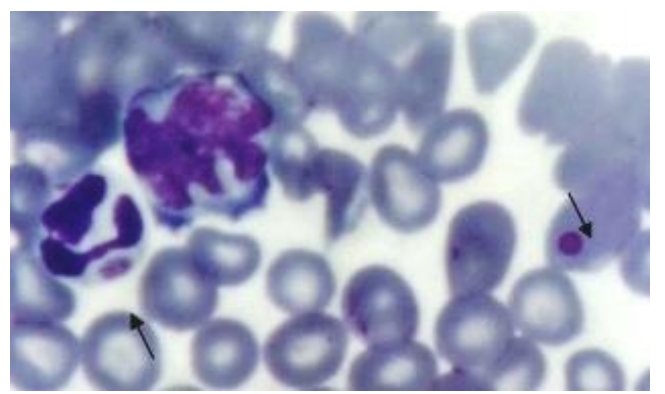

Figura 4. Inclusões de Lentz intra-eritrocitária e no citoplasma de leucócito (setas) de cães com suspeita clínica de cinomose. Fonte: Silva et al. (2005).

Greene \& Vandevelde (2015) apontam que as inclusões são visualizadas com maior frequência em linfócitos, embora possam ocorrer em monócitos, neutrófilos e eritrócitos, conforme figuras 5 e 6. 


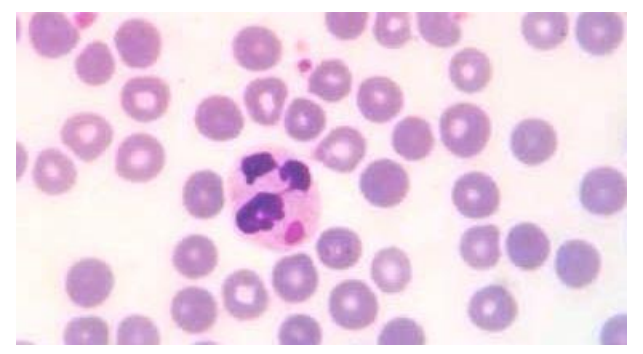

Figura 5. Corpúsculo de Lentz encontrado em neutrófilo segmentado. Fonte: Imagem gentilmente cedida pelo Laboratório de Análises Clínicas Veterinárias da Universidade Guarulhos, 2018.

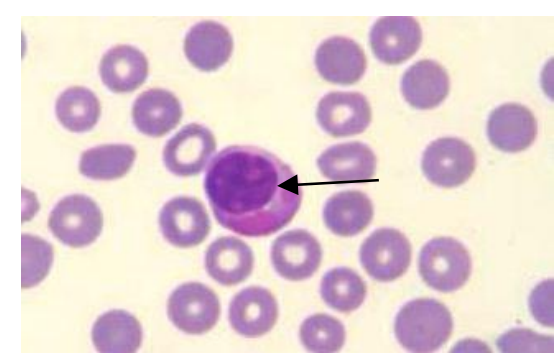

Figura 6. Corpúsculo de Lentz encontrado em linfócito (seta). Fonte: Imagem gentilmente cedida pelo Laboratório de Análises Clínicas Veterinárias da Universidade Guarulhos, 2018.

\section{Tratamento}

O tratamento, inicialmente, consiste em isolar o animal acometido para impedir que ocorra disseminação entre outros animais. A terapêutica no decorrer da abordagem clínica é de suporte e inclui fluidoterapia, antibioticoterapia, utilização de vitaminas, imunoestimulantes, anticonvulsivantes (se necessário), anti-eméticos em caso de sinais gastrointestinais e analgésicos (Crivellentin \& BorinCrivelletin, 2015; Greene \& Vandevelde, 2015). Azevedo (2013) recomenda, em casos de sinais gastrointestinais, que alimentos de fácil digestão e de consistência pastosa sejam administrados e para suporte terapêutico, sugere que seja administrado escopolamina, metoclopramida, ondasentrona ou dimenidrinato, sendo que o uso associado de ranitidina ou cimetidina favorece a proteção da mucosa gástrica. Neste caso, a fluidoterapia deve ser considerada e instituída. O uso de vitaminas do complexo $\mathrm{B}$ visa à estabilidade do metabolismo de neurotransmissores no animal acometido, além de agir na mielopoiese, estimular o apetite e ser anti-álgico. Em decorrência da formação de radicais livres, recomenda-se o uso de antioxidantes, tais como vitaminas $\mathrm{C}$ e E, para proteção do sistema nervoso (Azevedo, 2013; Gutiérrez et al., 2015; Spinosa et al., 1999).

Em caso de sintomatologia respiratória, pode-se utilizar ampicilina ou tetraciclina, atentando-se para a contra indicação de tetraciclinas em filhotes (Greene \& Vandevelde, 2015). Mangia \& Paes (2008) e Azevedo (2013) apontam que podem ser utilizados antimicrobianos de amplo espectro, tais como ampicilina, cloranfenicol, ceftiofur, fluorquinolonas, amoxicilina associada ao ácido clavulânico, cefalosporinas, e aminoglicosídeos e recomenda que a nebulização ou o uso de expectorantes, como Nacetilcisteína e bromexina, sejam associados. A ribavirina é um antiviral que tem sido utilizado nos tratamentos para cinomose. Acredita-se que seu mecanismo de ação atua interferindo na síntese de mRNA viral e inibe a formação de inosina monofosfato. Seu uso pode provocar aumento de bilirrubina, ferro e ácido úrico (Spinosa et al., 1999). Viana \& Teixeira (2015) apontaram que alguns animais tratados com ribavirina apresentaram queda acentuada na concentração de hemoglobina. Atualmente a ribavirina (30 mg/kg ao dia, via oral) tem sido associada ao uso do dimetil-sulfóxido (DMSO) na dose de $20 \mathrm{mg} / \mathrm{kg}$ ao dia de forma intravenosa, diluído em solução 10 a $20 \%$ de cloreto de sódio $(\mathrm{NaCl})$ a $0,9 \%$, ambos por 15 dias, sendo que desta forma, permite que ocorra maior difusão tecidual do fármaco, além de potencializar a ação antiviral da ribavirina (Torres \& Ribeiro, 2012).

O uso de glicocorticoides é contra indicado em caso de infecção aguda, porém pode favorecer o paciente que tenha sintomatologia neurológica (Nelson \& Couto, 2015). Mangia \& Paes (2008) apontam que o uso da dexametasona pode ser instituído para diminuir edema cerebral, mantendo doses antiinflamatórias. Devido ao efeito imunossupressor dos corticoides, podem-se favorecer novas infecções, além de provocar efeitos colaterais, bem como distúrbios gastrointestinais, em nível de sistema nervoso central, pode provocar aumento de apoptose neural e desmielinização, comprometendo ainda mais o prognóstico do animal acometido (Torres \& Ribeiro, 2012). Greene \& Vandevelde (2015) recomendam o uso de diazepam parenteral em caso de convulsão e fenobarbital como manutenção do quadro.

Em fase neurológica, a terapia suporte deve ser mantida e observada no intervalo de uma a duas semanas, porém, se houver progressão irreversível da piora clínica, a eutanásia deve ser considerada (Torres \& Ribeiro, 2012). O uso de imunomoduladores também é empregado, porém pode ter difícil acesso devido ao custo. A interferona age na célula do hospedeiro induzindo a formação de enzimas que diminuem a tradução do mRNA viral. Outra alternativa é o levamisol, um anti-helmíntico que atua como 
imuno modulador, pois estimula a produção de anticorpos (Spinosa et al., 1999). A utilização de soro hiperimune é outra alternativa para o tratamento, pois o mesmo pode levar à neutralização do vírus livre (Portela et al., 2017). Torres \& Ribeiro (2012) apontam que a sinvastatina pode ser utilizada em substituição aos corticoides após o tratamento e controle da doença, pois acredita-se que seu efeito diminua a carga inflamatória mediada no sistema nervoso e, consequentemente, a desmielinização.

Tratamentos complementares vêm sendo empregados para reabilitação e/ou melhora da qualidade de vida de animais que foram acometidos pela cinomose e mantiveram sequelas. A acupuntura e a fisioterapia atualmente proporcionam bons resultados e são indicadas em casos de paresias e paralisias, mioclonia, déficit de propriocepção, retenções urinária e fecal, incontinência urinária e atrofia muscular (Azevedo, 2013).

\section{Profilaxia}

Preconiza-se a utilização de vacinas atenuadas e polivalentes para a profilaxia da cinomose, sendo que a mesma possui agentes que previnem outras doenças, como leptospirose, parvovirose e hepatite infecciosa canina. Deve-se atentar às condições imunológicas do paciente, uma vez que a vacinação pode não ter resultado caso existam anticorpos maternos presentes ou o protocolo vacinal não tenha sido adequado (Gutiérrez et al., 2015). O neonato que recebe colostro da mãe tem imunidade entre uma a quatro semanas, devendo estabelecer o protocolo de vacinação após esse período. Geralmente a vacinação é realizada entre 6 e 16 semanas de vida (Greene \& Vandevelde, 2015). Segundo Angélico \& Pereira (2012) a vacinação deve ocorrer na oitava semana de vida, sendo necessário o reforço com mais duas doses após 3 a 4 semanas após a primeira aplicação.

Algumas cepas são comuns na grande variedade de vacinas disponíveis no mercado. Greene \& Vandevelde (2015) apontam que a cepa Onderstepoort não desenvolve a doença pós-vacinação, porém podem ocorrer níveis mais baixos de imunidade humoral, ainda assim é considerada eficiente e segura. A cepa Rockborn é capaz de produzir alta titulação de anticorpos, promovendo proteção por maior período de tempo, entretanto, há relatos de encefalite após a vacinação.

Há algumas variedades nas vacinas utilizadas, visando a resposta imune adequada. A vacina com vírus vivo modificado mantém o organismo causador da doença, porém não é patogênico, permitindo que haja resposta imunológica e consequente proteção em animais hígidos. Já a vacina inativada, possui um organismo inativo, incapaz de provocar doença, necessitando de doses múltiplas para atingir o objetivo imune (Day et al., 2016).

Greene \& Vandevelde (2015) apontam que as vacinas inativadas não produzem proteção imunológica completa, já o uso da vacina com vírus vivo modificado pode indicar resultados falsopositivos no soro até quatro semanas após vacinação. Preconiza-se ainda que a vacinação com a vacina viva deva ser trienal, porém devido às dificuldades de avaliar a titulação, geralmente é instituída a vacinação anual. Deve-se atentar a fatores concomitantes que podem afetar a eficácia da vacinação, como por exemplo, a imunossupressão, pois pode ter efeitos indesejados, além de possibilitar o desenvolvimento da doença.

\section{Considerações finais}

Visto que a cinomose canina é uma doença altamente contagiosa, de fácil disseminação e provoca altas taxas de óbito, deve-se atentar para a profilaxia, de modo que o protocolo instituído seja adequado para o animal em questão.

Uma avaliação clínica do estado geral do animal deve ser realizada para que possibilidades de contato e ou transmissão sejam evitadas.

Meios diagnósticos adequados devem ser solicitados em caso de suspeita, embora o histórico clínico demonstre maiores evidências.

O tratamento suporte deve ser iniciado o mais rápido possível após a confirmação da doença, de forma que auxilie o processo de ação do sistema imunológico para combater o agente patogênico em questão. 


\section{Referências bibliográficas}

Angélico, S. M. R. \& Pereira, C. A. D. (2012). Novas diretrizes vacinais para cães-uma abordagem técnica e ética. Revista Clínica Vetrinária, 17(97):68-80.

Azevedo, E. P. (2013). Abordagem ao paciente acometido por cinomose canina. Porto Alegre, Rio Grande do Sul Universidade Federal do Rio Grande do Sul.

Bento, M. S., Chamelete, M. O. \& Dantas, W. F. M. (2013). Diagóstico clínico e histopatológico de neoplasmas cutâneos em cães e gatos atendidos na rotina clínica do hospital veterinário da Univiçosa. ANAIS SIMPAC, 5(1).

Brito, L. B. S., Pereira, O. T., Oliveira, P. A. C., Teófilo, T. S., Oliveira, R. M., Silva, A. L. A. \& Torres, M. A. O. (2016). Aspectos epidemiológicos da cinomose em cães atendidos em um Hospital Veterinário no período de 2011 a 2013. PUBVET, 10(7):512-522.

Cowell, R. L. \& Tyler, R. D. (2009). Diagnostic cytology and hematology of the horse E-Book. Amsterdam, Holanda: Elsevier Health Sciences.

Crivellentin, L. Z. \& Borin-Crivelletin, S. (2015). Casos de rotina em medicina veterinária de pequenos animais. São Paulo.

Cubas, Z. S., Silva, J. C. R. \& Dias, J. L. C. (2014). Tratado de animais selvagens-medicina veterinária: Editora Roca.

Day, M. J., Horzinek, M. C., Schultz, R. D. \& Squires, R. A. (2016). Diretrizes para a vacinação de cães e gatos. Journal of Small Animal Practice, 57699-706.

Greene, C. E., Samperio, J. O. \& Gómez, J. P. (1993). Enfermedades infecciosas: Perros y gatos. São Paulo: Editora Interamericana.

Greene, C. E. \& Vandevelde, M. (2015). Cinomose. In C. E. Greene (Ed.), Doenças infecciosas em cães e gatos. Rio de Janeiro, Brasil: Guanabara Koogan.

Gutiérrez, M. M. B., Gutiérrez, J. A. O., Simón, M. T. C., Gómez, A. D., Bernal, G. D., Prieto, A. G., . . . Fernández, I. S. (2015). Manual gráfico de imunologia e enfermidades infecciosas do cão e do gato: MedVet.

Jericó, M. M., Kogika, M. M. \& Andrade Neto, J. P. (2015). Tratado de medicina interna de cães e gatos. Rio de Janeiro, Brasil: Guanabara Koogan.

Macedo, C. I., Peixoto, Z. M. P., Castilho, J. G., Oliveira, R. N., Rodrigues, A. C. \& Achkar, S. M. (2016). Diagnóstico de cinomose canina por RT-PCR em amostras de cães do estado de São Paulo enviadas para o diagnóstico laboratorial da raiva. Revista de Educação Continuada em Medicina Veterinária e Zootecnia do CRMV-SP, 14(1):18-21.

Mangia, S. H. \& Paes, A. C. (2008). Neuropatologia da cinomose. Veterinária e Zootecnia, 15(3):416427.

Nelson, R. W. \& Couto, C. G. (2015). Medicina interna de pequenos animais. Amsterdan: Elsevier Editora.

Portela, V. A. B., Lima, T. M. \& Maia, R. C. C. (2017). Cinomose canina: revisão de literatura. Medicina Veterinária (UFRPE), 11(3):162-171.

Silva, G. A., Araújo, E. K. D., Leite, A. G. P. M., Alencar, D. F., Prado, A. C., Oliveira, W. A. \& Cardoso, J. F. S. (2017). Parâmetros hematológicos de cães apresentando corpúsculos de lentz em esfregaço sanguíneo. PUBVET, 10(1):1022-1027.

Silva, I. N. G., Guedes, M. I. F., Rocha, M. F. G., Medeiros, C. M. O., Oliveira, L. C., Moreira, O. C. \& Teixeira, M. F. S. (2005). Perfil hematológico e avaliação eletroforética das proteínas séricas de cães com cinomose. Arquivo Brasileiro de Medicina Veterinária e Zootecnia, 57(1):136-139.

Spinosa, H. S., Górniak, S. L. \& Bernardi, M. M. (1999). Farmacologia aplicada à medicina veterinária. Rio de Janeiro: Guanabara Koogan.

Thrall, M. A. (2015). Hematologia e Bioquímica Clínica Veterinária. São Paulo, Brasil: Editora Roca.

Torres, B. B. J. \& Ribeiro, V. M. (2012). Cinomose nervosa canina: patogenia, diagnóstico, tratamento e prevenção. Revista de Cães e Gatos, 1(161):1-6. 
Tozato, C. d. C., Zadra, V. F., Basso, C. R. \& Araújo Junior, J. P. (2016). Canine distemper virus detection by different methods of One-Step RT-qPCR. Ciência Rural, 46(9):1601-1606.

Viana, K. F. \& Teixeira, N. S. (2015). Ribavirina e fase nervosa da cinomose: cura clínica, mas não esterilizante-Relato de dois casos. Brazilian Journal of Veterinary Medicine, 37(1):29-32.

Zachary, J. F., McGavin, D. \& McGavin, M. D. (2012). Bases da patologia em veterinária. Rio de Janeiro: Elsevier Brasil.

Recebido: 7 janeiro, 2019.

Aprovado: 23 janeiro, 2019

Publicado: 15 fevereiro, 2019

Licenciamento: Este artigo é publicado na modalidade Acesso Aberto sob a licença Creative Commons Atribuição 4.0 (CCBY 4.0), a qual permite uso irrestrito, distribuição, reprodução em qualquer meio, desde que o autor e a fonte sejam devidamente creditados. 